\title{
EVALUATION OF THE TRA ECETOC MODEL FOR INHALATION WORKPLACE EXPOSURE TO DIFFERENT ORGANIC SOLVENTS FOR SELECTED PROCESS CATEGORIES
}

\section{MAŁGORZATA KUPCZEWSKA-DOBECKA, SŁAWOMIR CZERCZAK, and MAREK JAKUBOWSKI}

Department of Chemical Safety

Nofer Institute of Occupational Medicine, Łódź, Poland

\begin{abstract}
Objective: The aim of this work is to describe the operation principle of the TRA ECETOC model developed using the descriptor system, and the utilization of that model for assessment of inhalation exposures to different organic solvents for selected process categories identifying a given application. Method: Measurement results were available for toluene, ethyl acetate and acetone in workplace atmosphere in Poland. The following process categories have been postulated: (1) Paints and lacquers factory: use in closed, continuous process with occasional controlled exposure; (2) Shoe factory: roller or brush application of glues; (3) Refinery: use in closed process, no likelihood of exposure. The next step was to calculate the workplace concentration at chosen process categories by applying the TRA ECETOC model. Results: The selected categories do not precisely describe the studied applications. Very high concentration values of acetone were measured in the shoe factory, mean $443 \mathrm{ppm}$. The concentration obtained with the aid of the model is underestimated, ranging from 25.47 to $254.7 \mathrm{ppm}$, for the case with and without activation of the local exhaust ventilation (LEV), respectively. Estimated concentration at a level corresponding to that of the measured concentration would be possible if the process category involving spraying, e.g., PROC 7 was considered. For toluene and ethyl acetate, the measured concentrations are within the predicted ranges determined with the use of the model when we assume the concentration predicted with active ventilation for the beginning, and the concentration predicted with inactive ventilation for the end of the range. Conclusions: Model TRA ECETOC can be easily used to assess inhalation exposure at workplace. It has numerous advantages, its structure is clear, requires few data, is available free of charge. Selection of appropriate process categories related to the uses identified is guarantee of successful exposure assessment.
\end{abstract}

Key words:

Inhalation exposure assessment, TRA ECETOC estimation, Organic solvents occupational exposure

\section{INTRODUCTION}

The process of developing an exposure scenario, i.e., a set of information describing conditions that enable controlling of the risks associated with identified uses of a chemical constitutes one of the stages of risk assessment in the workplace. The standard format of exposure scenario comprises short exposure scenario name, description of processes and activities included in the exposure scenario, operational conditions of use (e.g., exposure duration, frequency of use or quantity of used chemical, physical form, process temperature, etc.), necessary risk management measures (e.g., local exhaust ventilation,

Under project: Sixth Framework Programme OSIRIS (Optimized Strategies for Risk Assessment of Industrial Chemicals through Integration of Non-Test and Test Information). Received: Jan 25, 2011. Accepted: April 4, 2011.

Address reprint request to M. Kupczewska-Dobecka, Department of Chemical Safety, Nofer Institute of Occupational Medicine, św. Teresy 8, 91-348 Łódź, Poland (e-mail: dobecka@imp.lodz.pl). 
specified type of personal protection gear, effluent and waste cleaning, etc.) and also information on estimated exposure intensity and guidelines for the downstream users intended to help them assess if they operate within the limits specified by the exposure scenario.

According to the REACH regulation, each manufacturer and importer of chemical substances must prepare and assess exposure scenarios in his markets [1]. This could be improved by developing so-called generic exposure scenarios for various markets and products; the generic scenarios could be modified to suit individual cases. In this way, the manufacturer or importer would be able to associate the internal information on products, markets and customers with the information on exposure and product safety. For the downstream users, it would be practical to receive standardised exposure scenarios for specified uses of the substances in their sector instead of receiving a wide range of the scenarios from different suppliers. Short names may be helpful for the suppliers and receivers in arranging their mutual communication. Based on the short names, downstream user should be able to find out if the received exposure scenario may include a specified application. The downstream user should be able to describe the application he would like to communicate to the supplier. The short title of exposure scenario is intended to be a label, not the exposure scenario itself. Risk management measures and operational conditions shall remain to be the core of the exposure scenario. A standard description of applications is based on four elements: sector of use (SU), product category (PC), process category (PROC) and article category (AC). The standard description is available in the REACH computer system, i.e. IUCLID 5, as an aid in describing identified uses in register documents.

Product and process categories have been used to organize and group the identified uses for the purpose of preparing exposure scenarios, but also in dimensionless models that enable exposure assessment within the REACH system. Those descriptors have been prepared so that they can be used to identify suitable record relating to exposure assessment in one of the first-tier recommended tools, i.e. TRA ECOTOC (Targeted Risk Assessment) [2]. Product and process categories have been used to assign assumptions defined earlier, relating to exposure pathways, typical operational conditions and risk management measures in order to perform preliminary assessment of exposure with the aid of that model.

\section{OBJECTIVE}

The aim of this work is to describe the operation principle of the TRA ECETOC assessment model developed using the descriptor system, and the utilization of that model for assessment of inhalation exposures to different organic solvents for selected process categories identifying a given application.

\section{MATERIALS AND METHODS}

\section{Model approaches}

Many risk assessment models have been developed: simple in use but conservative - these are models of preliminary (first-tier) risk assessment that enable quick assessment of a specified range of exposure scenarios and risk management measures, such as the EUSES (The European Union System for the Evaluation of Substances) model and its EASE (Estimation and Assessment of Substance Exposure) module [3], but also models which require specialist knowledge to be operated successfully, enabling more precise assessment, for use only in circumstances when first-tier approach shows that problems may arise, e.g. in assessment of exposure to biocide products.

Process category elements constituted the basis of the EUSES system, and its advantage was that it required small amount of data for the first assessment. It is not clear, however, which operational conditions and risk management measures are considered as the applicable parameters. 
The limitations above have been the reason for developing the TRA ECETOC that uses the discussed application descriptors as a useful tool included in the information package and enabling assigning of a record to exposure assessment.

The focus of this work is on TRA ECETOC module, developed specifically with a view to enable assessment of exposure at workplace. Modules for assessing environmental exposures or consumer-commissioned exposure assessments are not discussed here. Categories used as records in that program refer to process category or technological activity with descriptor PROC attached to it. Process categories define typical exposure circumstances at workplace which can be also associated with default rough exposure levels. The descriptor system contains also a number of categories non-linked to default rough exposure levels which, nevertheless, may be suitable for description of applications.

Predefined exposure scenarios do not always comprise all relevant factors responsible for exposures within a specified application. In such instances, it is necessary to assess the possible effects of those factors on the exposure. To assign suitable categories to a specified application, it may be necessary to collect earlier a greater bulk of information about conditions of use, or apply the category of some other more suitable first-tier assessment tool. If it is not possible to obtain a satisfactory description of use with the aid of the accessible categories and one of the recommended first-tier tools, the standard algorithm of the procedure is interrupted and further development of the exposure scenario must be based on consideration of individual cases, which may require performing higher-tier assessments. For example, some operations performed at high temperatures in the metallurgical industry have not been considered as yet. No category has been defined for welding, soldering, gouging, brazing, flame cutting. In such instances, the respective industrial sector may start developing a suitable tool. Otherwise, the single registrant is obliged to perform relevant higher-tier assessment, based e.g. on measurement data supplied by the customers. Model lists for the selection of process descriptors have been developed, together with guidelines for their application, e.g. PROC 7 and 11 comprise spraying of paints, cleaners, air purifiers. PROC 13 has been assigned to washing of textiles and metal parts, dyeing and finishing of textiles, leather, paper, powder coating. PROC $10 \mathrm{com}$ prises floor coating, roller- or brush-painting of walls, printing operations, removing of substances by rubbing or brushing. Mechanical cutting, grinding, drilling, polishing is comprised in PROC 11. Mixing of solids and liquids in batch formulation of coatings, cleaners, plastics and dyes is included in PROC 3, while manual mixing of plaster corresponds to PROC 19.

\section{Operation principle of TRA ECETOC (worker model - v2.0)}

The TRA ECETOC model has been selected by ECHA as the preferred tool for assessing the extent of the inhalation exposure of workers. The ECETOC model had been recently updated on 24.03.2010, and this is the version which was tested. The hardcopy [4] and the internet [2] recent versions of the TRA ECETOC tool are available.

The ECETOC method for the assessment of the inhalation exposure is based on the EASE model, which is divided into the model of inhalation and dermal exposure. The model of inhalation exposure assumes that the concentration of a substance at workplace can be assayed through analogy with similar situations, in this particular case with situations in which the exposure concentrations have been measured. The characteristics of the inhalation exposure includes three modifying factor types that affect workplace exposures:

- substance's tendency to transform into the gaseous phase (physical condition),

- method of use of the substance - an extensive data base of exposures is used to calibrate the model, 
- means applied to control exposures or prevent the transfer of the substance to the workplace atmosphere.

The following input data referring to assessment of worker exposure are required to start the first-tier TRA ECETOC tool: specific data of substance, such as CAS number and name, molecular mass, physical and chemical form, fugacity of liquid substance, dustiness of solid substance. For each hazard category, a generic index exposure value is determined, corresponding to the indicative reference value, separately for the inhalation (volatile and solid substances) and dermal routes. Current TRA version uses the DNEL (Derived No Effect Level) as the reference value, but offers also the option to use OEL (occupational exposure limit), i.e., maximum admissible concentration at workplace. Information about substance's physical state should be duly taken into account. If the substance is liquid, data on fugacity should be specified. Depending on fugacity, the model classifies the volatility of the substance as low (vapour pressure $\geq 0.01<0.5 \mathrm{kPa}$ ), medium $(0.5$ to 10$)$ or high $(>10)$. When the fugacity of a liquid substance is below $0.01 \mathrm{~Pa}$, the system generates the information that the assessed exposure is $0.1 \mathrm{ppm}$, assuming that the employed process precludes formation of aerosol. When our response to the question about substance's state is „solid”, the software program will ask us if it is likely to cause dustiness. The table below shows the criteria that help us to classify the dustiness as low, medium or high.
The process adopted for risk assessment by TRA comprises 5 stages after loading of the input data.

1. Identification of activity/process category relevant to the substance and representing the intended conditions of its production, sale, supply and use. Thus, depending on the circumstances of production and use, it is likely that several scenarios are assigned to one substance. Suitable scenarios may be selected from the selection lists by specifying process category and selecting REACH process descriptor. Some PROC combinations with different input data are not possible. In such instance, the TRA ECETOC tool displays a message stating that it is necessary to change the input parameters, e.g. for PROC1 category, i.e. use in closed process, it is not possible to input data about the necessary use of ventilation.

2. Calculation of anticipated exposure with the use of relevant models.

3. Selection of suitable „no effect” level for the substance's risk category.

4. Determination of exposure margin through comparing the result of step (3) with that of step (2). The updated version uses the term ,risk characteristics ratio (RCR), which is the quotient of exposure and the reference value.

5. If risk cannot be suitably managed, risk management measures should be added and their expected effect on the predicted exposure level should be taken into

Table 1. TRA ECETOC Dustiness Assessment Criteria

\begin{tabular}{lclc}
\hline \multicolumn{1}{c}{ General description } & Relative dustiness potential & \multicolumn{1}{c}{ Typical material } & TRA Selection Value \\
\hline $\begin{array}{l}\text { Not dusty } \\
\text { Slightly dusty }\end{array}$ & 1 & $\begin{array}{l}\text { plastic granules, pelleted fertilizers } \\
\text { dry garden peat, sugar, salt }\end{array}$ & low \\
Dusty & $10-100$ times dustier & medium \\
Very/extremely dusty & $\begin{array}{c}\text { more than } 1000 \text { times } \\
\text { dustier }\end{array}$ & $\begin{array}{l}\text { cement dust, milled powders, plaster, flour, } \\
\text { freeze-dried powders, process fumes }\end{array}$ & high \\
\hline
\end{tabular}


account. In the target part of the ECETOC risk assessment concerned with workplace exposure, the user may activate the local ventilation option at the level of the first tier. This results in reduction of exposure level to a specified degree, depending on selected use categories and substance's volatility.

The ECETOC TRA tool currently does not contain a similar option for personal protection gear (such as masks, gloves). Nevertheless, when the risk management measure does not interact with exposure-related factors, it is possible to modify the results of exposure level determinations by accounting for the efficiency of that measure, e.g., semi-mask may be characterised by $90 \%$ efficiency at a given concentration of the substance in the ambient air. The effect of engineering exposure control measures (e.g., local exhaust ventilation) or use of closed process must be assessed separately for each individual case. Below is an example of exposure scenario builder using data sheet for modified process category (Table 2).

Table 2. Example of exposure scenario builder using data sheet for modified process category

\begin{tabular}{|c|c|}
\hline Step & $\begin{array}{l}\text { Operational conditions } \\
\text { and risk management measures }\end{array}$ \\
\hline \multicolumn{2}{|l|}{ Step 1. Select a REACH process descriptor } \\
\hline Enter a short scenario name & Formulation (industrial) \\
\hline Select a process category (PROC) & 5-Mixing or blending in batch processes \\
\hline Industrial or Public Domain & Industrial Activity or Public Domain (Professional) Activity \\
\hline \multicolumn{2}{|l|}{ Step 2. Apply Exposure Modifiers (Operational Conditions) } \\
\hline \multicolumn{2}{|l|}{ Ventilation } \\
\hline — Does this activity take place indoors or outdoors? & Indoors or Outdoors \\
\hline — Is local exhaust ventilation present? & No/Yes \\
\hline \multicolumn{2}{|l|}{ Duration of activity } \\
\hline \multirow[t]{4}{*}{ - What is the duration of the activity? } & $>4$ hours \\
\hline & 1-4 hours \\
\hline & 15 min -1 hour \\
\hline & $<15 \min$ \\
\hline \multicolumn{2}{|l|}{ Respiratory protection } \\
\hline \multirow[t]{3}{*}{ - What type of respiratory protection was used? } & Respiratory protection is not used \\
\hline & $\begin{array}{l}\text { Respiratory protection capable offering a } 90 \% \text { reduction in inhaled } \\
\text { concentrations of the substance }\end{array}$ \\
\hline & $\begin{array}{l}\text { Respiratory protection capable offering a } 95 \% \text { reduction in inhaled } \\
\text { concentrations of the substance }\end{array}$ \\
\hline \multicolumn{2}{|l|}{ Use in preparations } \\
\hline — Is the substance used in preparation? & No/Yes \\
\hline \multirow[t]{5}{*}{ - Select the concentration range $(\mathrm{w} / \mathrm{w})$} & Not in a mixture \\
\hline & $>25 \%$ \\
\hline & $5-25 \%$ \\
\hline & $1-5 \%$ \\
\hline & $<1 \%$ \\
\hline
\end{tabular}


The program enables generation of assessment report. For inhalation exposure, the estimated value is specified in terms of ppm. It is also possible to generate a linear report that may comprise estimates for all relevant exposure scenarios. In REACH Practical Guide is an example table reviewing first-tier exposure assessments, which is a part of the documentation in the chemical safety report [5]. The table contains examples of estimated exposure values for a solvent with a relatively low volatility $(1.13 \mathrm{hPa})$ and $50 \mathrm{ppm} \mathrm{OEL}$ (long-term inhalation exposure), for different conditions of use.

\section{Workplace atmosphere measurement results}

Measurement results were available for three organic solvents: toluene, ethyl acetate and acetone in workplace atmosphere in Poland. Xylene was measured only in the first factory.

Based on the description of job position, character of workplace, process type, job performed and working timetable, the following process categories have been postulated:

- Paints and lacquers factory, Synthesis section PROC 2, i.e., use in closed, continuous process with occasional controlled exposure (e.g., during sampling), with ventilation.

- Shoe factory: sole manipulation; sewing section, shoe assembly — PROC 10, i.e., roller or brush application of glues or other coatings. As full information on the workplace ventilation efficiency was not accessible, the assessment was performed for the process with and without ventilation, respectively.

- Refinery - PROC 1, i.e., Use in closed process, no likelihood of exposure

Table 3 shows measured concentrations of chosen organic solvents in workplace environment (in $\mathrm{mg} / \mathrm{m}^{3}$ ). Air sampling was by individual dosimeters, $7.5 \mathrm{~h}$ during 8 -h shift. Both in the Paints and Lacquers, and in the Shoe Factory, the organic solvents were present as components of formulations.
In the Shoe Factory, 12 different glues were used with a maximum content of $94.8 \%$ ethyl acetate, $87.37 \%$ acetone, $26.4 \%$ toluene. Workers were exposed to a mixture of solvents, because they stayed in one room. For the Paints and Lacquers factory, the content of the studied solvents in the mixture adopted for the calculations was: $1-5 \%$ for toluene, 5-25\% ethyl acetate, below $1 \%$ in the mixture for acetone and above $25 \%$ for o-xylene.

\section{Calculation of the workplace concentration by applying the TRA ECETOC model}

The next step was to calculate the workplace concentration at chosen process categories by applying the TRA ECETOC model. The input data required to assess worker exposure, such as molecular mass, physical and chemical form, fugacity of liquid substance, are obtained from IUCLID [6]. Process Category Identification using range sheet was done.

Maximum Admissible Concentration (MAC) value — the time-weighted average concentration for a conventional 8-hour workday, established in Poland for workplace air concentrations of substances was used as the reference: $100 \mathrm{mg} / \mathrm{m}^{3}$ for toluene and xylene, $200 \mathrm{mg} / \mathrm{m}^{3}$ for ethyl acetate and $600 \mathrm{mg} / \mathrm{m}^{3}$ for acetone [7].

Both the measured and the estimated data (in ppm and $\mathrm{mg} / \mathrm{m}^{3}$ ) obtained by applying the TRA ECETOC model to selected exposure scenarios are presented in Table 4.

\section{RESULTS}

Comparison of estimated data with values measured at workplace was done. Apparently, the selected categories do not precisely describe the studied applications. Very high concentration values of acetone were measured in the shoe factory at the shoe assembly workplaces, mean $443 \mathrm{ppm}\left(1053.4 \mathrm{mg} / \mathrm{m}^{3}\right)$. The concentration obtained with the aid of the model is underestimated, 
Table 3. Measured concentrations of chosen organic solvents in workplace environment (in $\mathrm{mg} / \mathrm{m}^{3}$ ) [8]

\begin{tabular}{|c|c|c|c|c|c|}
\hline Substance & $\begin{array}{l}\text { Paints and lacquers } \\
\text { factory synthesis } \\
\text { section filtration } \\
\& \text { decanting room }\end{array}$ & $\begin{array}{c}\text { Shoe factory } \\
\text { (sole manipulation) }\end{array}$ & $\begin{array}{c}\text { Shoe factory } \\
\text { (sewing section) }\end{array}$ & $\begin{array}{l}\text { Shoe factory } \\
\text { (assembling) }\end{array}$ & $\begin{array}{c}\text { Refinery supervisor, } \\
\text { process controller, } \\
\text { operator, } \\
\text { mechanician }\end{array}$ \\
\hline Toluene & $\begin{array}{l}\text { range: } 0.2-2.3 \\
\text { measured values: } 0.2 \\
0.4 ; 0.4 ; 0.5 ; 0.5 ; 0.5 ; \\
0.5 ; 0.6 ; 0.6 ; 0.7 ; 0.8 ; \\
0.8 ; 0.8 ; 0.9 ; 2.2 ; 2.3 \\
\text { mean: } 0.8 \\
\text { median: } 0.6\end{array}$ & $\begin{array}{l}\text { range: } 31.9-164.8 \\
\text { measured values: } \\
31.9 ; 34.9 ; 46.7 ; 57.2 ; \\
66.9 ; 84.4 ; 117.4 ; \\
164.8 \\
\text { mean: } 75.5 \\
\text { median: } 62.1\end{array}$ & $\begin{array}{l}\text { range: } 82.9-349.4 \\
\text { measured values: } \\
\text { 82.9; 85.9; 87.3; 90.9; } \\
\text { 101.3; 110; } 117.4 ; \\
117.7 ; 118.1 ; 119.7 ; \\
125.7 ; 142.4 ; 169.8 ; \\
181.4 ; 182.9 ; 190.9 ; \\
216 ; 221.5 ; 235.7 ; 259 ; \\
349.4 \\
\text { mean: } 157.4 \\
\text { median: } 125.7\end{array}$ & $\begin{array}{l}\text { range: } 43.9-69.9 \\
\text { measured values: } \\
43.9 ; 63.5 ; 67.7 ; 68.1 ; \\
69.9 \\
\text { mean: } 62.6 \\
\text { median: } 67.7\end{array}$ & $\begin{array}{l}\text { range: } 0.1-0.9 \\
\text { measured values: } 0.1 ; \\
0.1 ; 0.1 ; 0.1 ; 0.1 ; 0.1 ; \\
0.1 ; 0.1 ; 0.1 ; 0.1 ; 0.1 ; \\
0.1 ; 0.1 ; 0.2 ; 0.2 ; 0.3 ; \\
0.3 ; 0.4 ; 0.4 ; 0.4 ; 0.6 ; \\
0.7 ; 0.9 \\
\text { mean: } 0.25 \\
\text { median: } 0.1\end{array}$ \\
\hline Ethyl acetate & $\begin{array}{l}\text { range: } 1-37 \\
\text { measured values: } 1.0 \\
1.0 ; 1.3 ; 2.0 ; 2.5 ; 3.6 ; \\
4.6 ; 6.3 ; 7.7 ; 12.3 ; \\
16.9 ; 19.8 ; 31.2 ; 37 \\
\text { mean: } 10.5 \\
\text { median: } 5.5\end{array}$ & $\begin{array}{l}\text { range: } 29.5-45.2 \\
\text { measured values: } \\
\text { 29.5; } 30.3 ; 35.7 ; 36.9 ; \\
\text { 39.1; } 37.3 ; 39.8 ; 45.2 \\
\text { mean: } 36.7 \\
\text { median: } 38\end{array}$ & $\begin{array}{l}\text { range: } 77.6-348.6 \\
\text { measured values: } \\
77.6 ; 97.4 ; 105.4 ; \\
113.9 ; 118.3 ; 146.9 ; \\
149.3 ; 158.4 ; 163.4 ; \\
168 ; 190.1 ; 195.9 ; \\
197.8 ; 231.7 ; 238.1 ; \\
226.8 ; 240 ; 265.6 ; \\
276.9 ; 289.8 ; 348.6 \\
\text { mean: } 190.5 \\
\text { median: } 190.1\end{array}$ & $\begin{array}{l}\text { range: } 251.3-458.5 \\
\text { measured values: } \\
251.3 ; 357 ; 364 ; 411 ; \\
458.5 \\
\text { mean: } 368.3 \\
\text { median: } 364\end{array}$ & - \\
\hline Acetone & $\begin{array}{l}\text { range: } 0-0.8 \\
\text { measured values: } 0 ; 0 ; \\
0 ; 0 ; 0 ; 0 ; 0 ; 0 ; 0 ; 0 ; 0 ; \\
0 ; 0 ; 0 ; 0.7 ; 0.8 \\
\text { mean: } 0.09 \\
\text { median: } 0\end{array}$ & $\begin{array}{l}\text { range: } 52.8-85.7 \\
\text { measured values: } \\
\text { 58.2;63.3; 63.4; 75.3; } \\
77 ; 79.5 ; 81.1 ; 85.7 \\
\text { mean: } 72.9 \\
\text { median: } 76.2\end{array}$ & $\begin{array}{l}\text { range: } 43.3-192 \\
\text { measured values: } \\
\text { 43.3; 52.8; 53.2; 54.4; } \\
\text { 55.7; 61.4; 61.7; 61.9; } \\
62 ; 63.1 ; 73.3 ; 86.5 ; \\
\text { 90.6; } 97.4 ; 103.1 ; 108 ; \\
\text { 138.8; } 140.6 ; 142.5 ; \\
\text { 190.3; } 192 \\
\text { mean: } 92 \\
\text { median: } 73.3\end{array}$ & $\begin{array}{l}\text { range: } 782.3-1230.3 \\
\text { measured values: } \\
\text { 782.3; } 905.3 ; 1169.8 ; \\
1179.2 ; 1230.3 \\
\text { mean: } 1053.4 \\
\text { median: } 1169.8\end{array}$ & - \\
\hline o-Xylene & $\begin{array}{l}\text { range: } 2.4-20.9 \\
\text { measured values: } 2.4 ; \\
2.8 ; 3.1 ; 3.2 ; 3.9 ; 4.2 ; \\
8.3 ; 10.3 ; 10.4 ; 12 ; \\
20.9 \\
\text { mean: } 7.4 ; \\
\text { median: } 4.2\end{array}$ & - & - & - & - \\
\hline
\end{tabular}




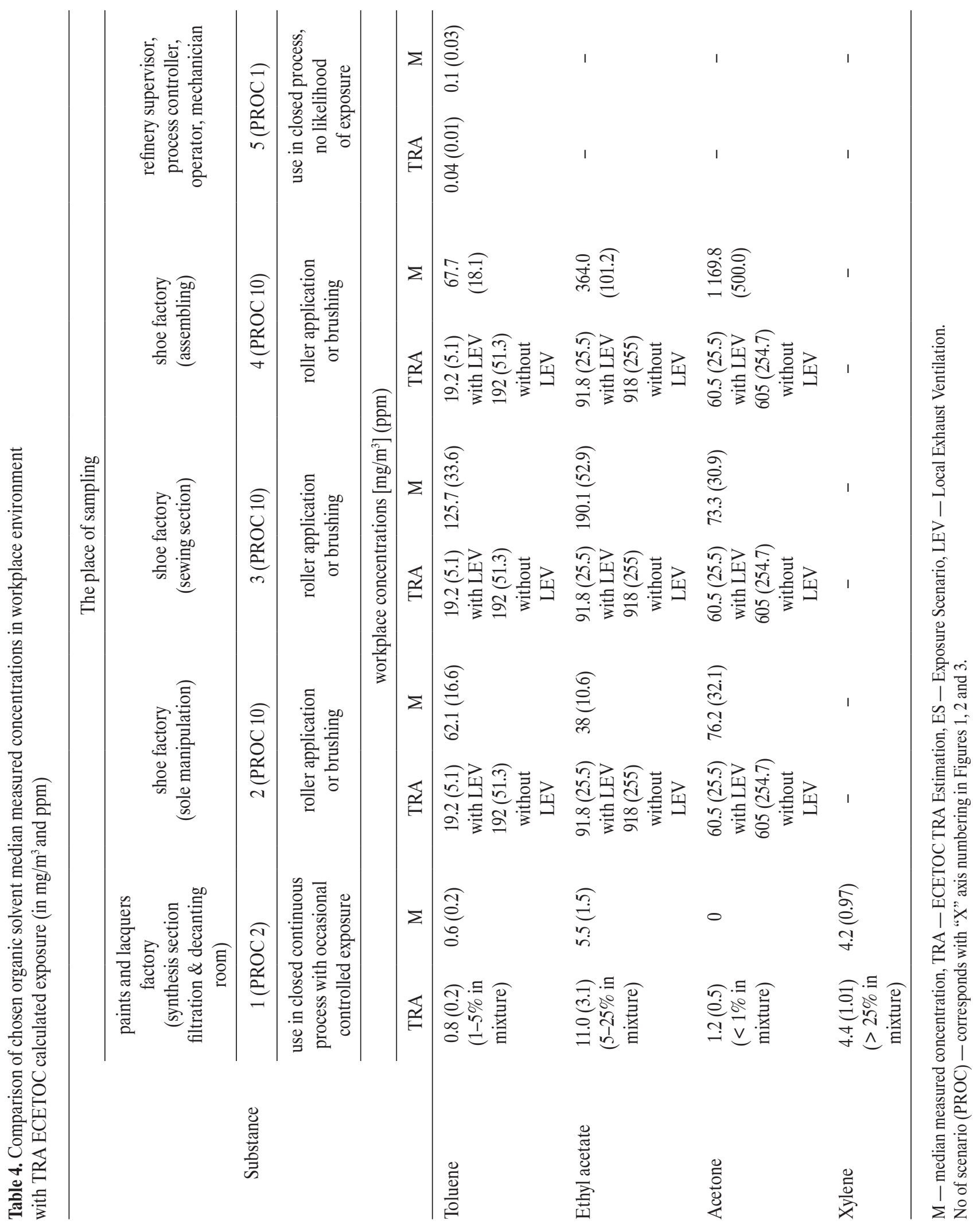


ranging from 25.47 to $254.7 \mathrm{ppm}\left(60.5\right.$ to $\left.605 \mathrm{mg} / \mathrm{m}^{3}\right)$, for the case with and without activation of the local exhaust ventilation, respectively. Estimated concentration at a level corresponding to that of the measured concentration would be possible if the process category involving spraying, e.g., PROC 7 was considered instead of application of the substance by brush. The documentation of the testing of workplaces at which measurements had been performed does not contain information whether the exposure was only to vapours, or to vapours and aerosols of the applied glue. To assign correct categories to a specified application, it may be necessary to collect earlier a greater bulk of information about relevant conditions of use. For toluene and ethyl acetate, the measured concentrations are within the predicted ranges determined with the use of the model when we assume the concentration predicted with active ventilation for the beginning, and the concentration predicted with inactive ventilation for the end of the range.

Is the risk associated with the identified uses of the substance suitably controlled when we take into account the set of information describing the conditions of use of the selected solvents? The calculated RCR coefficient is greater than 1 for PROC10 scenario with

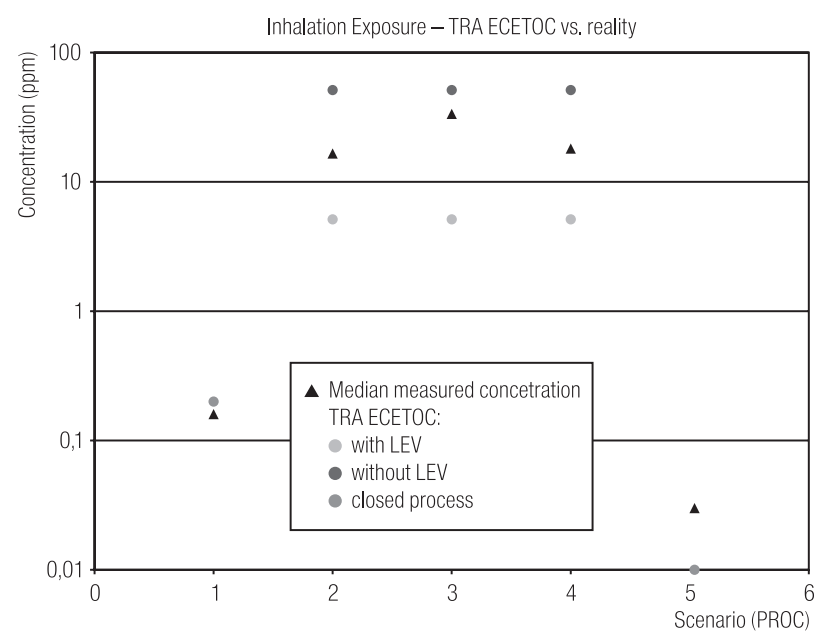

Fig. 1. Comparison of TRA ECETOC predictions and measurement data for toluene.

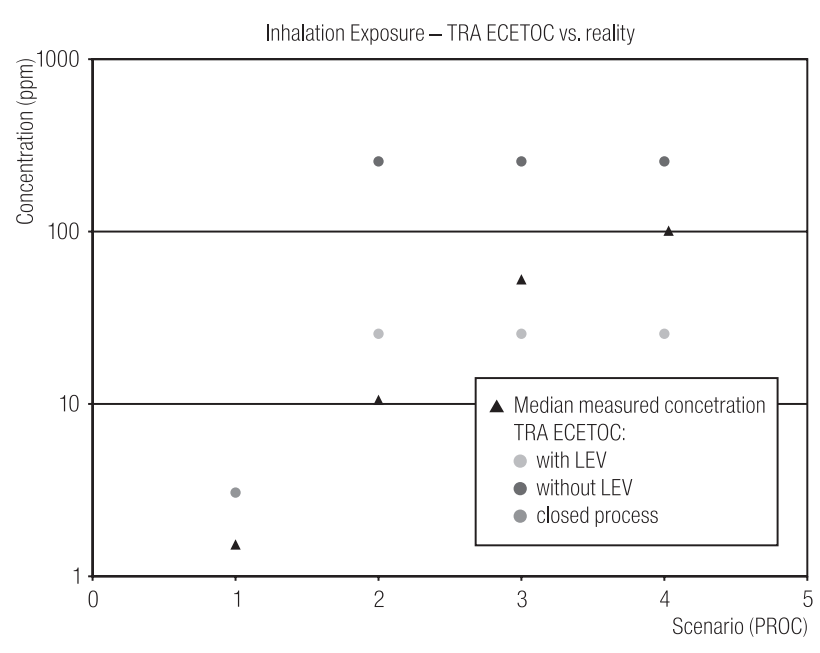

Fig. 2. Comparison of TRA ECETOC predictions and measurement data for ethyl acetate.

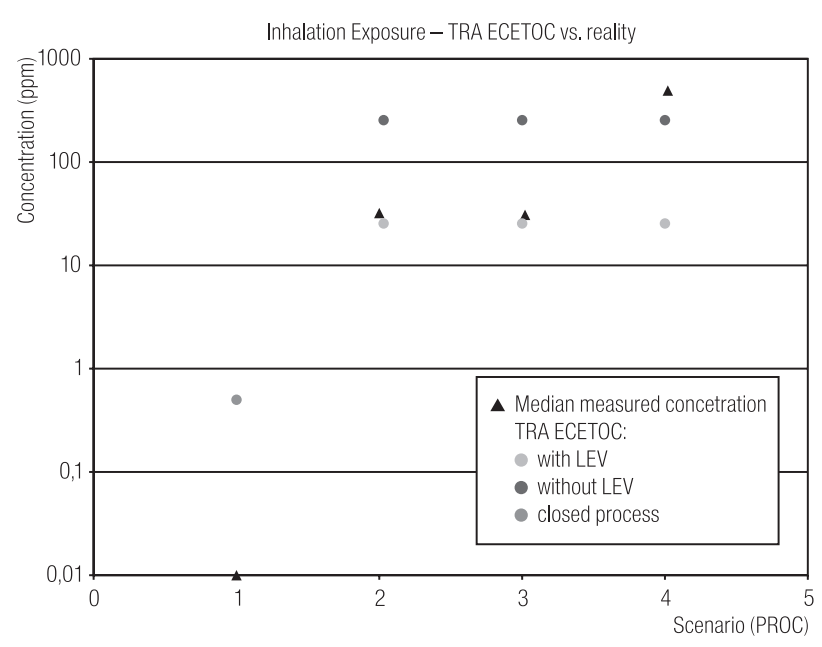

Fig. 3. Comparison of TRA ECETOC predictions and measurement data for acetone.

inactive ventilation option; its value is 1.9 for toluene and 4.6 for ethyl acetate. The risk estimation shows that the risk is not suitably controlled only in those two instances.

Figures 1-3 show both the calculated and the estimated data obtained by applying the TRA ECETOC model and EASE model to selected exposure scenarios. Numbers of scenarios in Figures 1-3 correspond to respective exposure scenarios in Table 4. 


\section{CONCLUSIONS}

1. Model TRA ECETOC can be easily used to assess inhalation exposure at workplace. It has numerous advantages, its structure is clear, requires few data, is available free of charge. The model is based on EU technological guidelines and it has been approved throughout the whole EU.

2. Selection of appropriate process categories related to the uses identified is guarantee of successful exposure assessment.

3. Increase of the number of separate scenarios, with a focus on careful handling situations is required in ECETOC TRA to increase its usefulness for assessment. At present, it is believed that the 25-29 scenarios are rather too few to describe the full set of possible situations.

4. Parameter associated with process category is used as the basis of the assessment, while process time is also taken into account. Some process categories seem to overlap, the choice of categories is not always clear and the number of the categories seems to be insufficient to cover every assessment. The program does not offer the option to account for the effect of varying quantity of material on the level of the exposure. „Local exhaust ventilation” is the only option directly selectable under „Risk control measures”; possible indirect measures include change/selection of process/activity/operational units, and duration.

5. Based on the TRA exposure estimation we conclude that the local exhaust ventilation during application of glues in the shoe factory is not sufficient.

6. The exposure scenario information gathering process should be directed to collect data necessary for exposure assessment. The documentation of the testing of workplaces at which measurements has been performed should contain information whether the exposure is only to vapours, or to vapours and aerosols. It is necessary to avoid underestimation of concentration of the substance.

\section{REFERENCES}

1. European Chemicals Agency. Guidance on information requirements and chemical safety assessment. Chapter R.14: Occupational Exposure Estimation. December 2009 (version 2 Rev.:0.0) [cited 2010 Dec 20]. Available from URL: http:/guidance.echa.europa.eu/docs/draft_documents/ R14_update_Version\%202_Rev00.pdf.

2. Targeted Risk Assessment (TRA) Tools [cited 2010 Jan 22]. Available from URL: http://www.ecetoc.org/tra.

3. Kupczewska-Dobecka M, Czerczak S, Jakubowski M, Maciaszek P, Janasik B. Application of predictive model to estimate concentrations of chemical substances in the work environment. Med Pr 2010;61(3):307-14 [in Polish].

4. European Centre for Ecotoxicology and Toxicology of Chemicals (ECETOC). Targeted Risk Assessment. Technical report No. 93. ECETOC, Brussels 2004.

5. European Chemical Industry Council. REACH Practical Guide on Exposure Assessment and Communication in the Supply Chains. Part 4: Supplement Exposure Estimation. May 2009 [cited 2011 Apr 06]. Available from URL: http:// www.esig.org/uploads/documents/105-641-doc-2-part4-practical-guidance-supplement-final.pdf.

6. European Commission Joint Research Centre. International Uniform Chemical Information Database [cited 2011 Apr 06]. Available from URL: http://ecb.jrc.ec.europa. $\mathrm{eu} / \mathrm{esis}$.

7. Regulation by the Minister of Labour and Social Policy on the Maximum Admissible Concentrations of harmful agents in the work environment. DzU No. 217, pos. 1833 (Nov 29, 2002) with amendments [in Polish].

8. Janasik B, Wesołowski W. Practical verification of usefulness of biological monitoring intended to assess exposures to volatile organic compounds (VOC) from determinations of their unchanged forms in urine. Report No ZCS/21.1/2006 on realisation of internal order No 2/06 under item IMP 4.11. Łódź: Nofer Institue of Occupational Medicine, 2006 [in Polish].

This work is available in Open Access model and licensed under a Creative Commons Attribution-NonCommercial 3.0 Poland License - http://creativecommons.org/ licenses/by-nc/3.0/pl/deed.en. 